\title{
NMR Study of Synthetic Gallosilicate Natrolite
}

\author{
M. Paczwa ${ }^{1}$ - A. A. Sapiga ${ }^{2}$ - M. Olszewski ${ }^{1}$ - A. V. Sapiga ${ }^{2}$ N. A. Sergeev ${ }^{1}$
}

Received: 24 June 2019 / Revised: 19 September 2019 / Published online: 4 October 2019

(c) The Author(s) 2019

\begin{abstract}
Solid-state ${ }^{29} \mathrm{Si}$ and ${ }^{71} \mathrm{Ga}$ NMR was used to study the synthetic gallosilicate $\mathrm{Na}_{16} \mathrm{Ga}_{16} \mathrm{Si}_{24} \mathrm{O}_{80} \cdot 16 \mathrm{H}_{2} \mathrm{O}$ ( $\mathrm{Ga}$-natrolite). It has been shown that Ga-natrolite contains mainly $\mathrm{Si}\left(\mathrm{GaO}_{4}\right)_{3}\left(\mathrm{SiO}_{4}\right)$ and $\mathrm{Si}\left(\mathrm{GaO}_{4}\right)_{2}\left(\mathrm{SiO}_{4}\right)_{2}$-structural units and has sufficiently ordered structure. Temperature dependence of the spin-lattice relaxation time $T_{1}$ of ${ }^{71} \mathrm{Ga}$ nuclei has also been studied using solid-state NMR. Spin-lattice relaxation of the ${ }^{71} \mathrm{Ga}$ was determined to be governed by the electric quadrupole interaction with the crystal electric field gradients modulated by translational motion of $\mathrm{H}_{2} \mathrm{O}$ molecules in the $\mathrm{Ga}-$ natrolite pores.
\end{abstract}

\section{Introduction}

Nowadays, there has been considerable interest in the isomorphous replacement of $\mathrm{Al}$ atoms by other trivalent cations due to the increased interest in zeolites. These micro-porous species possess different physical and chemical properties from their aluminium analogues and offer possibilities for new applications of molecular sieves [1-5]. Gallium is directly below aluminium in the periodic table; therefore, it forms chemically similar, analogous tetrahedra to $\mathrm{AlO}_{4}$. Isomorphous substitution of $\mathrm{Ga}$ for $\mathrm{Al}$ in alumosilicate natrolite $\left(\mathrm{Na}_{16} \mathrm{Al}_{16} \mathrm{Si}_{24} \mathrm{O}_{80} \cdot 16 \mathrm{H}_{2} \mathrm{O}\right)$ gives gallosilicate natrolite (Ga-natrolite) [1].

NMR spectroscopy is one of the main methods for studying the microstructure of materials, including zeolites [6]. In present paper, the structure of orthorhombic synthetic gallosilicate natrolite $\left(\mathrm{Na}_{16} \mathrm{Ga}_{16} \mathrm{Si}_{24} \mathrm{O}_{80} \cdot 16 \mathrm{H}_{2} \mathrm{O}\right)$ was studied by means of NMR MAS of ${ }^{29} \mathrm{Si}$ and ${ }^{71} \mathrm{Ga}$ nuclei. The temperature dependence of the spin-lattice

N. A. Sergeev

mykola.serheiev@usz.edu.pl

A. V. Sapiga

sapiga_av@mail.ru

1 Department of Mathematics and Physics, Institute of Physics, University of Szczecin, Szczecin, Poland

2 Physical-Technical Institute, V.I. Vernadsky Crimean Federal University, Simferopol 295007, Russian Federation 
relaxation time $\mathrm{T}_{1}$ of ${ }^{71} \mathrm{Ga}$ nuclei has also been studied using solid-state NMR. Obtained results were compared with available references [7-15].

\section{Experimental Procedure}

Gallium form of natrolite was hydrothermally synthesized as described in [12]. Water solution of gallium oxide $\left(\mathrm{Ga}_{2} \mathrm{O}_{3}, 99.99+\%\right.$, Aldrich $)$ and sodium hydroxide (50\% aqueous solution, Aldrich) was heated up to $100{ }^{\circ} \mathrm{C}$ and stirred over night. After cooling to room temperature, colloidal silica (Ludox AS-40) was slowly added, with stirring. Result mixture with oxide composition of $6.0 \mathrm{Na}_{2} \mathrm{O} \cdot 1.0 \mathrm{Ga}_{2} \mathrm{O}_{3}$. $10.0 \mathrm{SiO}_{2} \cdot 150 \mathrm{H}_{2} \mathrm{O}$ was charged into Teflon-lined $100 \mathrm{~mL}$ autoclave and heated up to $170{ }^{\circ} \mathrm{C}$. After 12 days, the autoclave was cooled down. Products were washed three times with water and dried over night in the oven.

Powder X-ray data (XRD) were collected on PANalytical XPERT-PRO diffractometer using $\mathrm{Cu}-\mathrm{K} \alpha$ radiation source $(\lambda=1.541874 \AA$ A). Samples were analyzed over the $2 \theta$ range of $5-70^{\circ}$ with the step size of $0.017^{\circ}$ (Fig. 1). Phases were identified by comparing diffraction peaks with the data reported in Inorganic Crystal Structure Database (ICSD) using X'Pert HighScore program. According to ICSD, obtained XRD pattern matches NAT topology and it is in a good agreement with material TNU-4 as in [12]. This suggests that experimental material is gallium form of natrolite.

Chemical analyses of synthesized gallium natrolite and natural natrolite were performed using DSM 982 Gemini FE-SEM scanning electron microscope (SEM) ZEISS. The detector consisted of the inlens and lateral electron (SE) detector and the backscatter electron (BSE) detector. BSE detector was used most frequently for individual SEM images. Respective excitation voltage was $0.265 \mathrm{keV}$. Details of

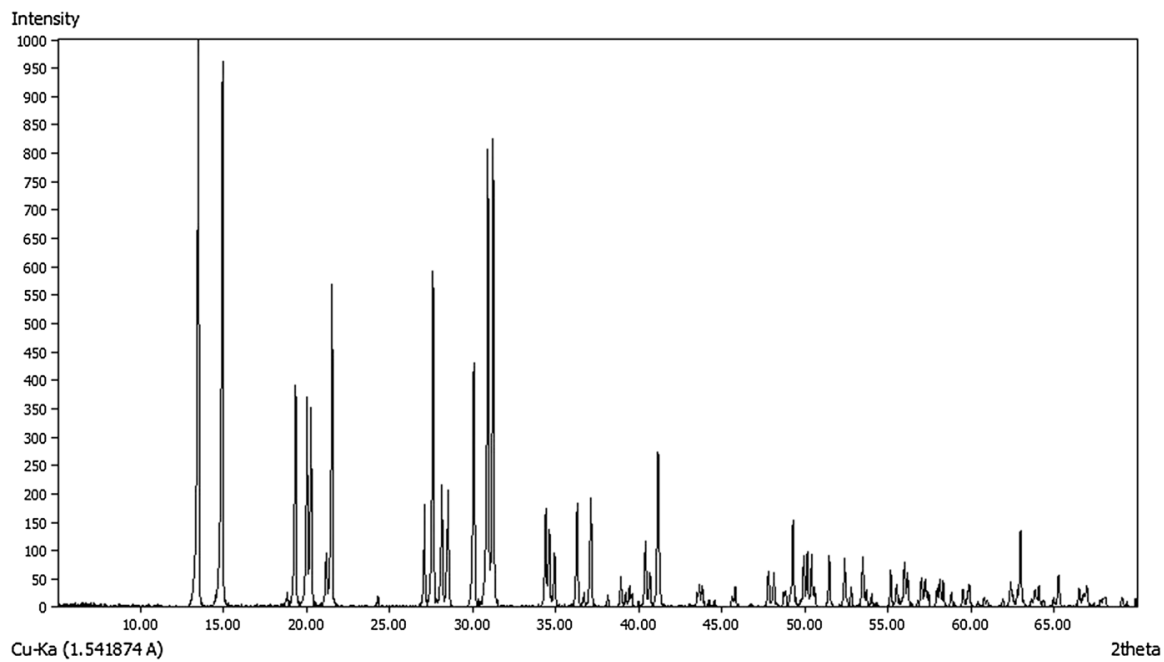

Fig. 1 Powder X-ray diffraction pattern of gallium natrolite prepared in this study 
Table 1 Data of chemical analyses of $\mathrm{Ga}$ natrolites

\begin{tabular}{llllll}
\hline Sample & $\mathrm{Si}$ & $\mathrm{Ga}$ & $\mathrm{Na}$ & $\mathrm{O}$ & $\mathrm{Si} / \mathrm{M}$ \\
\hline Ga-natrolite & 15.41 & 9.85 & 8.73 & 66.02 & 1.565 \\
\hline
\end{tabular}

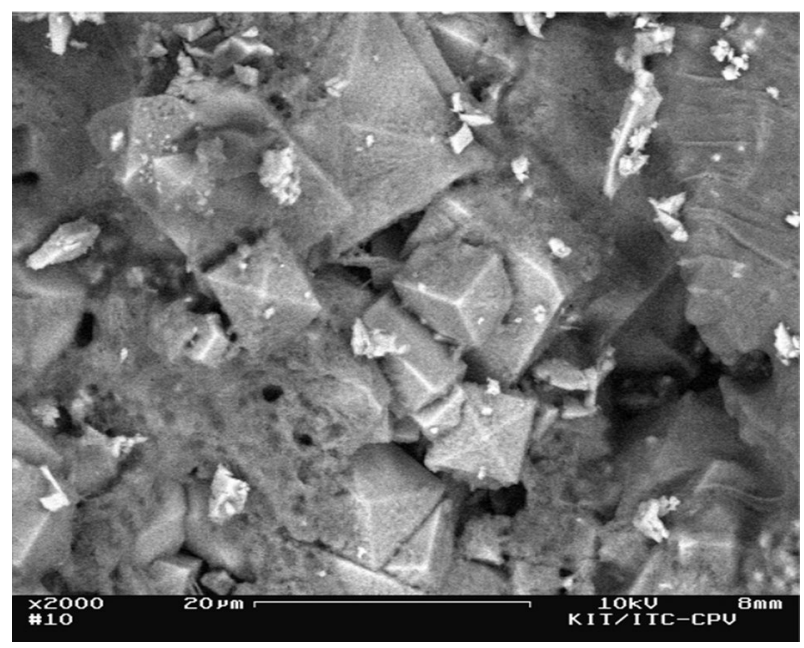

Fig. 2 Scanning electron micrographs of the gallium natrolite

chemical analyses can be found in Table 1. SEM picture of small crystals produced by hydrothermal synthesis can be found in Fig. 2 .

NMR MAS spectra were obtained on polycrystalline sample of Ga-natrolite on a Bruker Avance-400 NMR spectrometer. ${ }^{29}$ Si MAS NMR spectra were measured at a spinning rate of $10 \mathrm{kHz}$ using $4 \mathrm{~mm}$ rotors at a ${ }^{29} \mathrm{Si}$ frequency of $79.490 \mathrm{MHz}$ with $\pi / 2$ pulse length of $3 \mu \mathrm{s}$. Typically, 10,000 scans were accumulated and the ${ }^{29} \mathrm{Si}$ chemical shifts were referenced to TMS. ${ }^{71} \mathrm{Ga}$ MAS NMR spectra were obtained at a ${ }^{71} \mathrm{Ga}$ frequency of $122.0564 \mathrm{MHz}$ in $4 \mathrm{~mm}$ rotors at a spinning rate of $14.0 \mathrm{kHz}$ with an acquisition of 1000 pulse transients, which was repeated with RF pulse length of $2.4 \mu \mathrm{s}$. The Dmfit program [16] was used to simulate ${ }^{71} \mathrm{Ga}$ spectra to extract isotropic chemical shifts $\left(\delta_{\text {iso }}\right)$, quadrupolar coupling constants $\left(C_{\mathrm{Q}}\right)$, and asymmetry parameters $(\eta)$. The spin-lattice relaxation time $\mathrm{T}_{1}$ for ${ }^{71} \mathrm{Ga}$ nuclei was measured by the saturation-recovery method.

\section{Results and Discussion}

Figure 3 shows ${ }^{29} \mathrm{Si}$ MAS NMR spectra of Al-and Ga-natrolites. From these figure, it follows that ${ }^{29} \mathrm{Si}$ MAS NMR spectra of $\mathrm{Al}-$ and $\mathrm{Ga}$-natrolite are similar and contain two resonant lines. In natural Al-natrolite, two resonance lines of ${ }^{29} \mathrm{Si}$ MAS NMR spectrum at $-84.9 \mathrm{ppm}$ and $-92.7 \mathrm{ppm}$ with an intensity ratio of $\approx 2: 1$ were observed in our investigations (Fig. 3). 

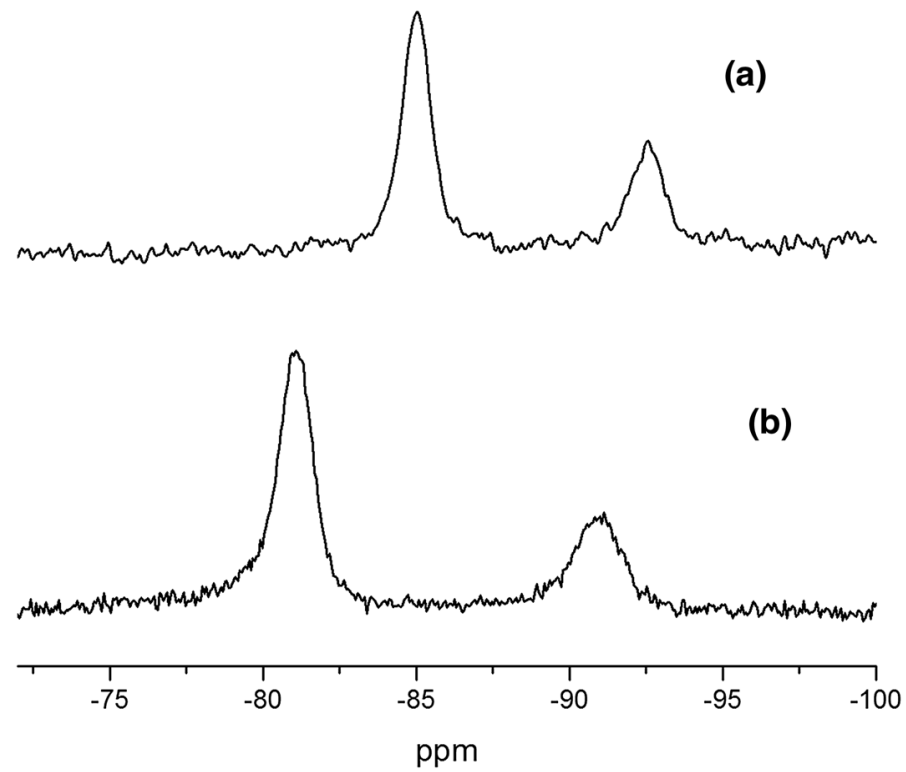

Fig. $3{ }^{29}$ Si MAS NMR spectra of Al-natrolite [13] (a) and Ga-natrolite (b)

The number of resonance NMR lines of the nuclei ${ }^{29} \mathrm{Si}$ and ${ }^{71} \mathrm{Ga}$ determined by the degree of ordered of the natrolite structure $[6,14,17]$. It has been demonstrated at first by Lipmaa et al. [17] that chemical shifts of ${ }^{29} \mathrm{Si}$ MAS NMR spectra of zeolite and other aluminoosilicates are sensitive to the number of $\mathrm{AlO}_{4}$ tetrahedra linked to the $\mathrm{SiO}_{4}$ tetrahedron, also described as the second coordination sphere of silicon. The number of aluminium tetrahedra sharing oxygens with the $\mathrm{SiO}_{4}$ tetrahedron defines five different structural units in the alumosilicate framework, namely, $\mathrm{Si}(\mathrm{nAl})$, where index $n=0,1,2,3,4$ specify the number of aluminium tetrahedra connected with $\mathrm{SiO}_{4}$ tetrahedron. ${ }^{29} \mathrm{Si}$ chemical shift ranges by about $5 \mathrm{ppm}$ lowfield shifts for each additional connected substituent [17]. This allows to establish structures of various zeolites and get information about $\mathrm{Si} / \mathrm{Al}$ ordering.

The orthorhombic Al-natrolite (space group Fdd2) has three different central sites (T-sites) in $\mathrm{TO}_{4}$ tetrahedra with multiplicities 8:16:16. According to the X-ray and NMR structure determination study [17, 18], the structure of natural Al-natrolite is well-ordered with $\mathrm{Si} / \mathrm{Al}$ ratio of $3: 2[6,17]$. There are two types of species with silicon atoms containing $\mathrm{Si} / \mathrm{Al}$ ratio of 1.5, i.e., those connected to three $\mathrm{AlO}_{4}$ tetrahedra and one $\mathrm{SiO}_{4}$ tetrahedron $\left(\mathrm{Si}\left(\mathrm{AlO}_{4}\right)_{3}\left(\mathrm{SiO}_{4}\right)\right)$ and those connected to two $\mathrm{AlO}_{4}$ tetrahedra and two $\mathrm{SiO}_{4}$ tetrahedra $\left(\mathrm{Si}\left(\mathrm{AlO}_{4}\right)_{2}\left(\mathrm{SiO}_{4}\right)_{2}\right)$ in 2:1 ratio [17].

Two resonance lines at $-81.1 \mathrm{ppm}$ and $-91.1 \mathrm{ppm}$ observed in NMR MAS ${ }^{29} \mathrm{Si}$ spectrum (Fig. 3) of gallosilicate natrolite may indicate that the natrolite has sufficiently well-ordered structure and mainly contains $\mathrm{Si}\left(\mathrm{GaO}_{4}\right)_{3}\left(\mathrm{SiO}_{4}\right)$ and $\left.\mathrm{Si}\left(\mathrm{GaO}_{4}\right)_{2}\left(\mathrm{SiO}_{4}\right)_{2}\right)$ structural units. However, the intensity ratio of these two lines $(\approx 1.7)$ is somewhat unusual and has an $\mathrm{Si} / \mathrm{Ga}$ ratio different than 1.5. This suggests that in the structure of gallosilicate natrolite, there are other $\mathrm{Si}\left(\mathrm{GaO}_{4}\right)_{n}\left(\mathrm{SiO}_{4}\right)_{4-n}$ species with $n=0,1,4$ structural 
units [11]. Intensities of NMR MAS ${ }^{29} \mathrm{Si}$ lines of these units may be too weak to be observed experimentally [11]. The difference of chemical shifts between two resonance lines of ${ }^{29} \mathrm{Si}$ atoms in $\mathrm{Ga}$-natrolite is $10.0 \mathrm{ppm}$.

Gallium atoms have four nearest-neighbour oxygen atoms in tetrahedral coordination in Ga-natrolite. The nucleus of gallium atom has the spin of $I=3 / 2$ and it is a quadrupolar nucleus. The quadrupole moment of the nucleus is a sensitive probe of the existence of a nonuniform electric field (EFG) at the location of the nucleus. The experimental and simulated ${ }^{71} \mathrm{Ga}$ MAS NMR spectra of $\mathrm{Ga}$-natrolite are shown in Fig. 4 which clearly shows a line shape that is determined by the second-order quadrupolar interaction $[19,20]$.

The experimental temperature dependence of the spin-lattice relaxation time $T_{1}$ of ${ }^{71} \mathrm{Ga}$ nuclei in Ga-natrolite is shown in Fig. 5. It is important to note that the relaxation process for ${ }^{71} \mathrm{Ga}$ nuclei in $\mathrm{Ga}$-natrolite was well described by a single exponential. It can be assumed that the main physical mechanism responsible for spin-lattice relaxation of ${ }^{71} \mathrm{Ga}$ nuclei in $\mathrm{Ga}$-natrolite is identical with the mechanism of spin-lattice relaxation of ${ }^{27} \mathrm{Al}$ nuclei in $\mathrm{Al}-$ natrolite and the spin-lattice relaxation of ${ }^{71} \mathrm{Ga}$ nuclei in $\mathrm{Ga}$-natrolite is concerned with modulation of electric quadrupolar interactions at the sites of the ${ }^{71} \mathrm{Ga}$ nuclei by thermal motion of water molecules [14]. In this case, the rate of spin-lattice relaxation of ${ }^{71} \mathrm{Ga}$ nuclei may be described by the equation as [14, 20-23]

$$
R_{1 \mathrm{Q}} \equiv T_{1 \mathrm{Q}}^{-1} \cong \alpha \cdot \overline{\left(\delta C_{\mathrm{Q}}\right)^{2}}\left[\frac{\tau_{\mathrm{c}}}{1+\omega_{0}^{2} \tau_{\mathrm{c}}^{2}}+\frac{4 \tau_{\mathrm{c}}}{1+4 \omega_{0}^{2} \tau_{\mathrm{c}}^{2}}\right] \text {, }
$$

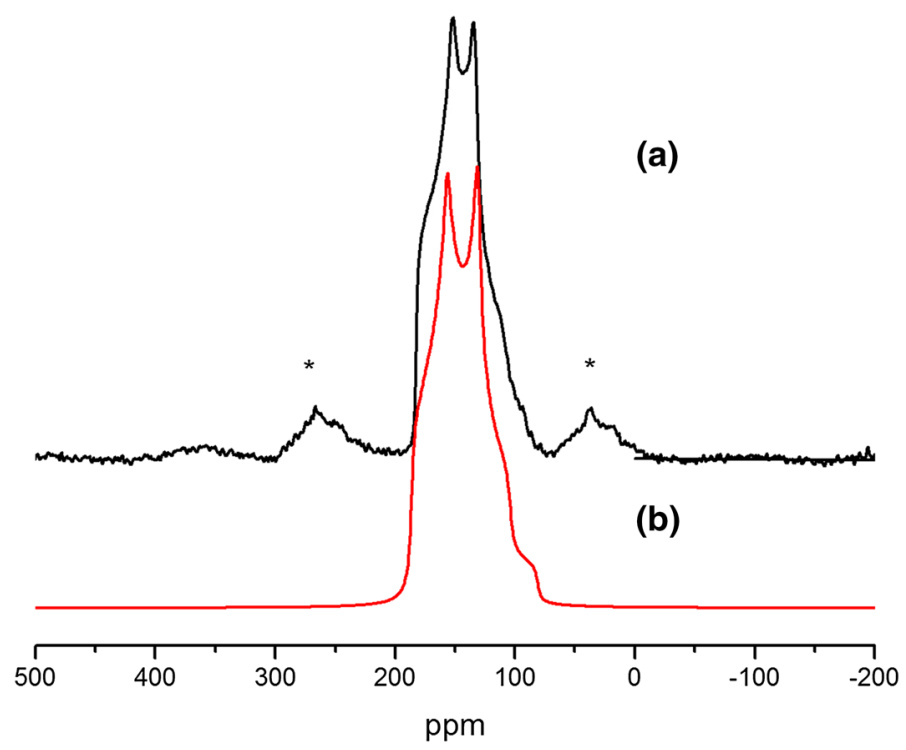

Fig. $4{ }^{71} \mathrm{Ga}$ MAS NMR spectra of Ga-natrolite. a Experimental spectrum at $T=300 \mathrm{~K}$. b Theoretical spectrum with parameters: the quadrupole coupling constant $C_{\mathrm{Q}}=e^{2} \mathrm{qQ} / h=5 \mathrm{MHz}$; the asymmetry parameter $\eta=0.5$; chemical shift $\delta_{\text {iso }}=190.54 \mathrm{ppm}$. Spinning sidebands are marked by asterisks 


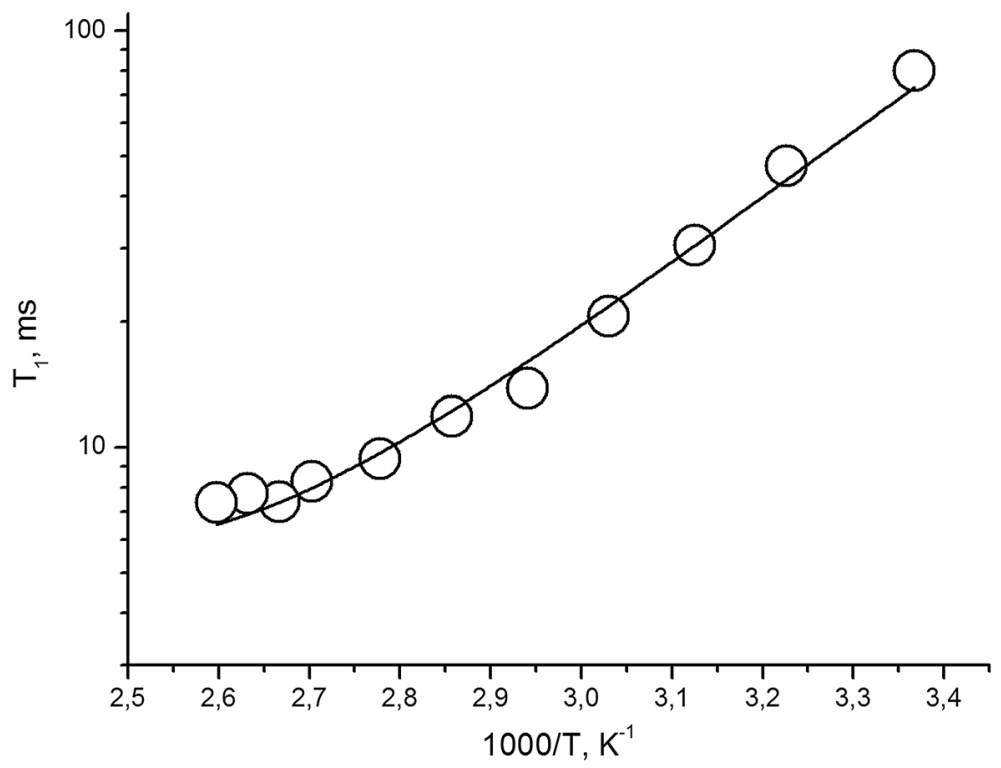

Fig. 5 Temperature dependences of the spin-lattice relaxation rate of the ${ }^{71} \mathrm{Ga}$ nuclei in Ga-natrolite. Experimental (circles) and theoretical (continuous line)

where parameter $\alpha$ depends on the asymmetry parameter $\eta$ of the EFG (from the estimations $\alpha \approx 0.13-0.17$ [23]); $\omega_{0}$ is the Larmor frequency of the quadrupole nucleus and

$$
\delta C_{\mathrm{Q}}=\frac{e^{2}(\delta q) Q}{\hbar}
$$

describes fluctuations of the quadrupole coupling constant [20] at the sites of the ${ }^{71} \mathrm{Ga}$ nuclei, $\tau_{\mathrm{c}}$ is the correlation time, which describes activated translational and reorientational jumps of electric dipoles in water molecules. In Eq. (1), $\overline{(\cdots)}$ represents an ensemble average.

From Eq. (1) ,it follows that $R_{1 \mathrm{Q}} \sim \tau_{\mathrm{c}}$ for $\omega_{0} \tau_{\mathrm{c}}<<1$, while $R_{1 \mathrm{Q}} \sim 1 / \tau_{\mathrm{c}}$ for $\omega_{0} \tau_{\mathrm{c}}>>1$, with a maximum of $R_{1 \mathrm{Q}}$ (and minimum of $T_{1 \mathrm{Q}}$ ) in the intermediate region. We assume that the correlation time $\tau_{\mathrm{c}}$ caused by the molecular motion follows the Arrhenius-type temperature dependence [20]:

$$
\tau_{\mathrm{c}}=\tau_{0} \exp \left(E_{\mathrm{a}} / R T\right) .
$$

Translational and reorientational jumps of electric dipoles of water molecules were assumed to be dynamically heterogeneous (i.e., described by different activation energies $E_{\mathrm{a}}$ ), and as a result, these were characterized by a normal distribution of the activation energies [24]:

$$
p\left(E_{a}\right)=\frac{1}{\sqrt{2 \pi \sigma_{E}}} \exp \left\{\frac{E_{a}-\bar{E}_{a}}{2 \sigma_{E}^{2}}\right\} .
$$


Table 2 Calculated parameters that describe the contribution $R_{1 Q} \equiv T_{1 Q}^{-1}$ to the spin-lattice relaxation

\begin{tabular}{|c|c|c|c|}
\hline$\sqrt{\alpha \cdot \overline{\left(\delta C_{\mathrm{Q}}\right)^{2}}}, \operatorname{rad~MHz}$ & $\tau_{0}, \mathrm{~s}$ & $\bar{E}_{\mathrm{a}}, \mathrm{kcal} / \mathrm{mol}$ & $\sigma_{\mathrm{E}}, \mathrm{kcal} / \mathrm{mol}$ \\
\hline 0.3 & $10^{-13}$ & 7.3 & 0.022 \\
\hline
\end{tabular}

Therefore, Eq. (1) was averaged over distribution function of Eq. (4). Experimental temperature dependence of the spin-lattice relaxation time and results of their approximation by function of Eq. (1) are presented in Fig. 5. Obtained adjusting parameters are given in Table 2.

Obtained activation energy $7.3 \mathrm{kcal} / \mathrm{mol}$ strongly suggests that translational and reorientational jumps of electric dipoles of water molecules are responsible for the relaxation process of the ${ }^{71} \mathrm{Ga}$ nuclei.

According to the data presented in Table 1, averaged fluctuations of quadrupole coupling constant at the sites of the ${ }^{71} \mathrm{Ga}$ nuclei are

$$
\sqrt{\overline{\left(\delta C_{\mathrm{Q}}\right)^{2}}} \approx 0.3 \mathrm{MHz} .
$$

Full constant of quadrupolar interaction for the ${ }^{71} \mathrm{Ga}$ nuclei in the natrolite $C_{\mathrm{Q}}=\mathrm{eqQ} / h=5 \mathrm{MHz}$, and therefore, the contribution of the electric dipolar moments of the water molecules to the full EFG at the ${ }^{71} \mathrm{Ga}$ sites is $6 \%$.

\section{Conclusions}

Based on the analysis of obtained NMR MAS spectra of ${ }^{29} \mathrm{Si}$ and ${ }^{71} \mathrm{Ga}$ nuclei in $\mathrm{Ga}-$ natrolites, synthetic gallosilicate natrolite has a well-ordered structure with $\mathrm{Si} /$ $\mathrm{Ga}$ ratio (3:2) and it contains $\left(\mathrm{Si}\left(\mathrm{GaO}_{4}\right)_{3}\left(\mathrm{SiO}_{4}\right)\right)$ and $\left(\mathrm{Si}\left(\mathrm{GaO}_{4}\right)_{2}\left(\mathrm{SiO}_{4}\right)_{2}\right)$ tetrahedra in the $2: 1$ ratio. From experimental and simulated ${ }^{71} \mathrm{Ga}$ MAS NMR spectrum of Ga-natrolite, it follows that NMR line shape is determined by the second-order quadrupolar interaction. The spin-lattice relaxation of the ${ }^{71} \mathrm{Ga}$ is governed by electric quadrupole interaction with crystal electric field gradients modulated by translational motion of $\mathrm{H}_{2} \mathrm{O}$ molecules in natrolite pores.

Acknowledgements We thank Olaf Walter for XRD pattern studies, Philipp Becker for participation in hydrothermal synthesis, Wilhelm Habicht for scanning electron/scanning probe microscopy, from Institute of Technical Chemistry Division of Chemical-Physical Processing (ITC/CPV), Karlsruhe Institute of Technology (KIT).

Open Access This article is distributed under the terms of the Creative Commons Attribution 4.0 International License (http://creativecommons.org/licenses/by/4.0/), which permits unrestricted use, distribution, and reproduction in any medium, provided you give appropriate credit to the original author(s) and the source, provide a link to the Creative Commons license, and indicate if changes were made. 


\section{References}

1. D.W. Breck, Zeolite Molecular Sieves (Wiley, New York, 1974)

2. J. Weitkamp, in Catalysis and Absorption by Zeolites, ed. by G. Olhmann, J.C. Vedrine, P.A. Jacobs (Elsevier, Amsterdam, Netherland, 1991), p. 21

3. J.M. Newsam, in Solid State Chemistry Compounds, ed. by A.K. Cheetham, P. Day (Oxford University Press, Oxford, 1992), pp. 234-280

4. S.M. Auerbach, H.I. Metiu, J. Chem. Phys. 106(7), 2893 (1997)

5. J.B. Nagy, R. Aiello, G. Giordano, A. Katovic, F. Testa, Z. Kónya, I. Kiricsi, Mol. Sieves 5, 365 (2007)

6. G. Engelhardt, D. Michel, High-Resolution Solid-State NMR of Silicates and Zeolites (Wiley, New York, 1987), p. 150

7. S.B. Hong, S.H. Kim, Y.G. Kim, Y.C. Kim, P.A. Barrett, M.A. Camblor, J. Mater. Chem. 9, 2287 (1999)

8. S.B. Hong, S.H. Lee, C.-H. Shin, A.J. Woo, J.L. Alvarez, M.C. Zicovich-Wilson, M.A. Camblor, J. Am. Chem. Soc. 126(42), 13742 (2004)

9. A. V. Sapiga, Thesis, Tavrida National University at the name of V.I.Vernadsky, Simferopol, Ukraine, 2003

10. M. Paczwa, Thesis, Department of Mathematics and Physics, Institute of Physics, University of Szczecin, Poland, 2017

11. H.K.C. Timken, E. Oldfield, J. Am. Chem. Soc. 109, 7669 (1987)

12. H.H. Cho, S.H. Kim, Y.G. Kim, Y.C. Kim, H. Koller, M.A. Camblor, S.B. Hong, Chem. Mater. 12, 2292 (2000)

13. A.A. Sapiga, M. Olszewski, M. Paczwa, A.V. Sapiga, N.A. Sergeev, Funct. Mater. 21, 181 (2014)

14. M. Paczwa, A.A. Sapiga, M. Olszewski, N.A. Sergeev, A.V. Sapiga, Appl. Magn. Reson. 46, 583 (2015)

15. A.M. Panich, I.A. Belitskii, N.K. Moroz, S.P. Gabuda, V.A. Drebushchak, Yu.V. Seretkin, J. Struct. Chem. 31, 56 (1990)

16. D. Massiot, F. Fayon, M. Capron, I. King, S. Calve, B. Alonso, J.-O. Durand, B. Bujoli, Z. Gan, G. Hoatson, Magn. Reson. Chem. 40, 70 (2002)

17. E. Lippmaa, M. Magi, A. Samoson, M. Tarmak, G. Engelhardt, J. Am. Chem. Soc. 103, 4992 (1981)

18. W.M. Meier, Z. Kristallogr. 113, 430 (1960)

19. D. Freude, in Encyclopedia of Analytical Chemistry, ed. by R.A. Meyers (Wiley, Chichester, 2000), p. 12188

20. A. Abragam, The Principles of Nuclear Magnetism (Oxford U.P, London, 1961), Chap. X, p. 467

21. V.I. Chizhik, Nuclear Magnetic Relaxation (LGU, Leningrad, 1991), p. 99, Eq. (3.111)

22. J. Haase, H. Pfiefer, W. Oehme, J. Klinowski, Chem. Phys. Lett. 150, 189 (1988)

23. J. Haase, K.D. Park, K. Guo, H.K.C. Timken, E. Oldfield, J. Phys. Chem. 95, 6996 (1991)

24. A.V. Sapiga, N.A. Sergeev, Cryst. Res. Technol. 36, 8 (2001)

Publisher's Note Springer Nature remains neutral with regard to jurisdictional claims in published maps and institutional affiliations. 